\title{
Dual controls on carbon loss during drought in peatlands
}

\author{
Hongjun Wang ${ }^{1,2 \star}$, Curtis J. Richardson ${ }^{1 \star}$ and Mengchi $\mathrm{Ho}^{1}$
}

Peatlands store one-third of global soil carbon'. Drought/drainage coupled with climate warming present the main threat to these stores ${ }^{1-4}$. Hence, understanding drought effects and inherent feedbacks related to peat decomposition has been a primary global challenge ${ }^{5,6}$. However, widely divergent results concerning drought in recent studies ${ }^{3,7-11}$ challenge the accepted paradigm that waterlogging and associated anoxia are the overarching controls locking up carbon stored in peat. Here, by linking field and microcosm experiments, we show how previously unrecognized mechanisms regulate the build-up of phenolics, which protects stored carbon directly by reducing phenol oxidase activity during short-term drought and, indirectly, through a shift from low-phenolic Sphagnum/herbs to high-phenolic shrubs after long-term moderate drought. We demonstrate that shrub expansion induced by drought/warming $2,6,10,12,13$ in boreal peatlands might be a long-term self-adaptive mechanism not only increasing carbon sequestration but also potentially protecting historic soil carbon. We therefore propose that the projected 'positive feedback loop' between carbon emission and drought in peatlands ${ }^{2,3,14,15}$ may not occur in the long term.

Peatlands, covering only 3\% of Earth's land area, store about $445 \mathrm{Pg}$ of carbon $^{1}$. These stores result from a small imbalance between production and decomposition over millennia under predominantly waterlogged conditions. However, drought and drainage coupled with warming have been substantially lowering water levels for decades and have resulted in a degradation of more than $11 \%$ of global peatlands ${ }^{1}$. These hydrologic shifts often threaten carbon stores, changing peatlands from a carbon sink to a carbon source by increasing decomposition ${ }^{2,3,14-16}$; concomitantly, the crucial peat-forming Sphagnum mosses are replaced by shrubs/trees ${ }^{2,10,12}$ with possibly substantial feedbacks on climate change $e^{6,10}$. However, recent evidence showed that in some peatlands drought had little impact or even decreased $\mathrm{CO}_{2}$ emission and increased carbon accumulation ${ }^{7-11,17-19}$ (Supplementary Table 1). These contrasting results raise uncertainty on the future fate of peat carbon and question the conventional theory that anoxia is the key to sustaining peat carbon.

Detailed comparisons of these drought studies (for example, refs 2,3,7-11,14,15,17,18) show that the initial water level and dominant species varied before drought manipulation (Supplementary Table 1), indicating that these peatlands were in different successional stages ${ }^{6}$. In Sphagnum peatlands, where water levels were mostly above or near the ground surface, drought increased $\mathrm{CO}_{2}$ emission. However, drought seemed to have less impact in unsaturated and shrub/tree-dominated peatlands.

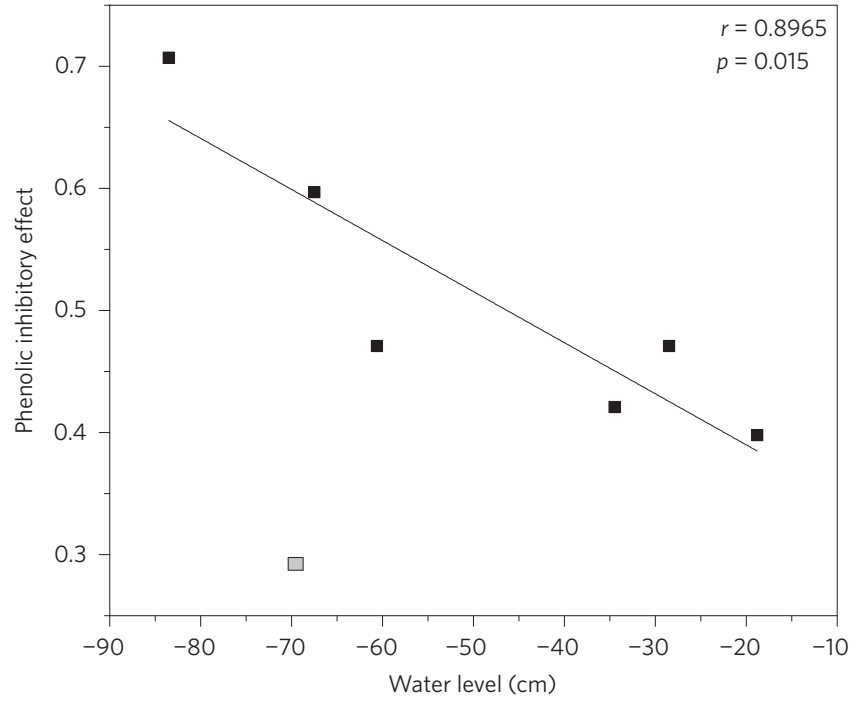

Figure 1 | Phenolic inhibitory effect on soil respiration versus annual average water level. Phenolic inhibitory effect is defined as a negative value of Pearson's $r$ between soil respiration and soluble phenolics in the surface soil. The grey square is one masked value (removed from the regression) in a drained site where samples were collected around a big pine tree.

Autotrophic SR from tree roots may have been the main contributor to the high total SR recorded, thus affecting readings in this site. Water level is measured relative to the ground surface.

Therefore, unrecognized adaptive mechanisms rather than anoxia must exist and inhibit carbon loss in unsaturated peatlands. Here, we provide new evidence on how a dual mechanism controlling phenolics build-up is the key to long-term carbon storage under drought using five integrated field and laboratory experiments.

Our study sites $\left(35^{\circ} 37^{\prime}-35^{\circ} 44^{\prime} \mathrm{N}, 76^{\circ} 27^{\prime}-76^{\circ} 35^{\prime} \mathrm{W}\right)$ were located in pocosin peatlands, which cover millions of hectares in the southeastern US (ref. 20). Shrubs have been dominant species here for more than 3,000 years ${ }^{20}$. Pocosins are rarely inundated and often experience severe summer drought, for example, in 2011 (Supplementary Fig. 1), yet continue to accrete carbon at a rate 25 times higher than in boreal peatlands ${ }^{11,20,21}$. Pocosins are mature shrub peatlands and the resilient mechanisms that have developed in these systems over millennia might be more obvious than in other recent shrub-expanded boreal peatlands.

To explore the unknown mechanism of peat carbon preservation we first monitored soil respiration (SR) and related biotic/abiotic parameters in natural, drained and restored pocosins.

\footnotetext{
${ }^{1}$ Duke University Wetland Center, Nicholas School of the Environment, Box 90333, Duke University, Durham, North Carolina 27708, USA. ${ }^{2}$ State Key Laboratory of Vegetation and Environmental Change, Institute of Botany, Chinese Academy of Sciences, Xiangshan, Beijing 100093, China.

*e-mail: hw93@duke.edu; curtr@duke.edu
} 


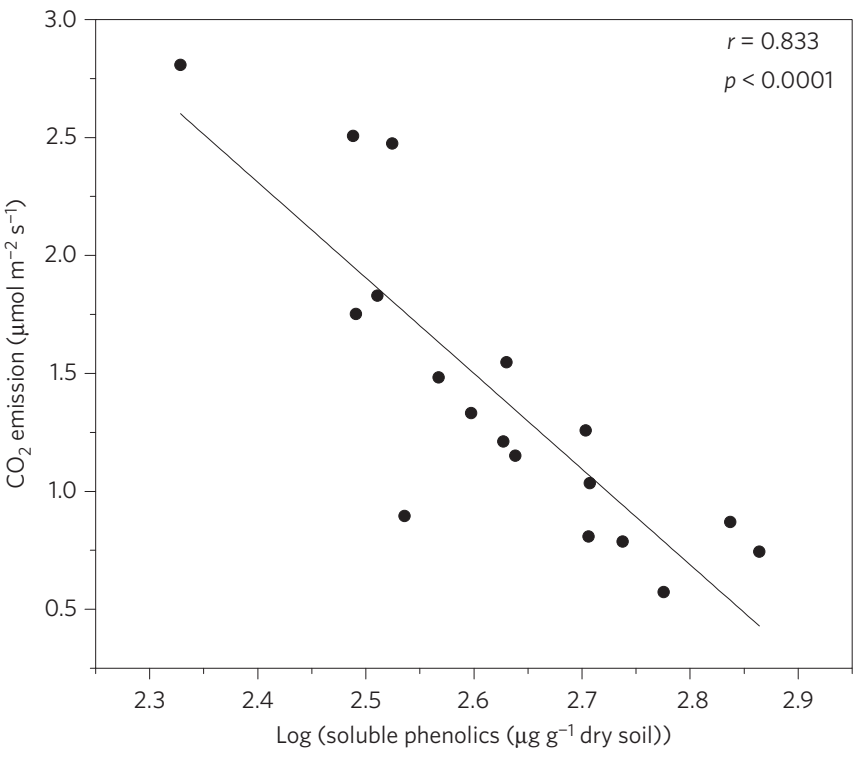

Figure 2 | Heterotrophic $\mathrm{CO}_{2}$ emission versus soluble phenolics during the initial 60-day drought incubation in all peat monoliths from pocosin peatlands.

Here, SR includes both heterotrophic respiration of microbes (HR) and autotrophic respiration of roots and associated mycorrhizae (AR), but only HR contributes to peat decomposition. For the past two decades, hydrologic differences among our sites have changed the plant communities and soil biogeochemistry (Supplementary Tables 2 and 3). Mature canopy trees, ferns and shrubs dominate in the natural, drained and restored sites, respectively. Loss on ignition of soil, $\mathrm{C} / \mathrm{N}$ ratios in leaves and stems, and total phenolics in leaves were lower in drained sites than other sites. The natural site had higher total soil nitrogen and the highest above-ground biomass $\left(71.9 \mathrm{MgC} \mathrm{ha}{ }^{-1}\right)$ compared with restored $\left(20.1 \mathrm{MgC} \mathrm{ha}^{-1}\right)$ and drained $\left(4.8 \mathrm{MgC} \mathrm{ha}^{-1}\right)$ sites, thus emitting the highest $\mathrm{CO}_{2}$ (Supplementary Fig. 2), possibly mainly from AR. As in other wooded peatlands $s^{7,8,11}$, drainage did not raise SR (Supplementary Fig. 2), although more reactive nitrogen was available in drained sites compared with restored sites (Supplementary Table 3). Two environmental variables consistently affected the temporal dynamics of SR in each site. Soil temperature explained $80-91 \%$ of the SR dynamics (Supplementary Fig. 3). The second variable was phenolics, which was negatively related to SR, and importantly this relationship was stronger at the drier sites (Fig. 1). Therefore, it seems that phenolics, acting as anti-microbial and anti-enzymatic compounds ${ }^{15}$, increasingly inhibited microbial and enzyme activity and hence reduced HR under drought. However, a possible increase in AR under drought might mask the reduction of HR, leading to contrasting and often incorrect conclusions when using total SR (HR $+\mathrm{AR})$ to evaluate the drought effects on peat decomposition.

To examine whether $\mathrm{HR}$ is inhibited during short-term drought and how long-term hydrologic conditions impact this, we collected peat monoliths from natural, drained and restored pocosins and incubated them in open-top microcosms creating drought conditions by evaporation. The fresh litter, live roots and rhizomes ( $>1 \mathrm{~mm}$ diameter) were removed to exclude AR. Over 5 months, about $42 \%$ of soil water was lost in all monoliths (Supplementary Fig. 4a). HR decreased 53\% in the restored and 80\% in the natural/drained sites within $60 \mathrm{~d}$ before reaching a similar asymptote (Supplementary Fig. 5). As both labile polysaccharide and water-extracted dissolved organic carbon did not decrease temporally (Supplementary Fig. 4c,d) and HR was uncorrelated to soil moisture, HR was unlikely limited by available carbon and soil moisture. These results matched our field observations and clearly

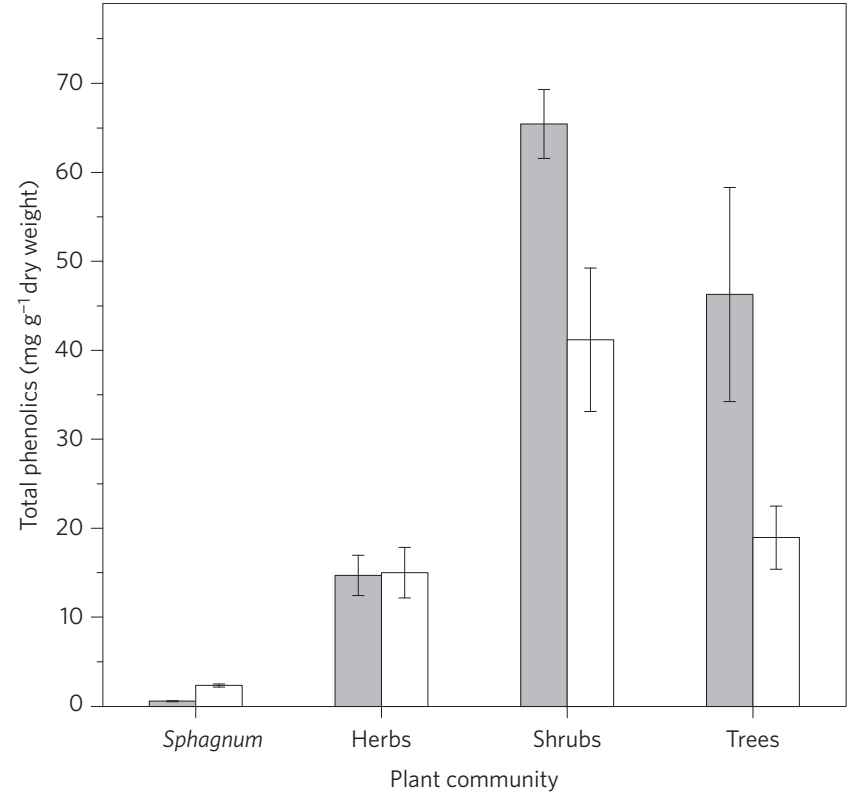

Figure 3 | Total phenolics in leaves in pocosins (grey column) and in leaf litter in boreal peatlands (plain column) from different plant communities. Error bars are standard errors of the mean.

showed that phenolics significantly inhibited HR (Fig. 2). During drought phenolics built up (Supplementary Fig. 4b), which was probably caused by reduced phenol oxidase activity (Supplementary Fig. 4e) through soil moisture limitation (Supplementary Fig. 6). This gives evidence that phenol oxidase activity has an optimal soil moisture ${ }^{22,23}$, above which anoxia inhibits activity (as in most boreal peatlands $s^{3}$ ) and below which drought limits activity ${ }^{24}$. Most wooded peatlands ${ }^{10}$, like pocosins, stay in unsaturated conditions, and more phenolics consequently exist under shortterm drought ${ }^{22,25}$, thereby preventing peat oxidation. However, this cannot be sustained with long-term severe drought, such as in our drained sites, where long-term drainage shifted plant communities, causing lower phenolics and higher available nitrogen in soil, with resulting higher HR (Supplementary Figs $4 \mathrm{~b}, \mathrm{f}$ and 5, and Supplementary Table 3). Although in situ SR levels from drained and restored sites were similar (Supplementary Fig. 2), higher biomass in the restored sites possibly caused higher AR that offset higher HR indicated by our in-laboratory drought experiment in the drained sites.

We consider phenolics build-up during short-term drought as an inherent resilience in peatlands. Why have such processes been detected only in wooded peatland ${ }^{22,23,25}$, and not in Sphagnum peatlands? We postulate that the quantity and quality of phenolics differ greatly in shrub/tree versus Sphagnum/herb, and this difference is a key factor controlling long-term peat conservation in wooded peatlands. To illustrate this, we measured water-soluble and total phenolics in senesced leaves of most species in pocosins and compared our results with the published data in boreal peatlands (Supplementary Table 4). In both pocosins and boreal peatlands, shrubs contained the highest phenolics, followed by trees and herbs, with Sphagnum mosses the lowest (Fig. 3). Importantly, the water-soluble phenolics in shrubs were 10 times higher than those in Sphagnum although the ratio of water-soluble to total phenolics was higher in Sphagnum (76\%) than in shrubs (6\%). Additionally, shrubs produce much longer-chain phenolic ${ }^{26}$ with higher resistance to breakdown, whereas the limited supply of phenolics in Sphagnum hinders such resistance. Therefore, shrub expansion in boreal peatlands not only produces high-phenolic litter but also introduces more phenolics to protect Sphagnum peat. In European peatlands, shrub expansion has been shown to raise phenolics in both litter and pore water ${ }^{2}$. 


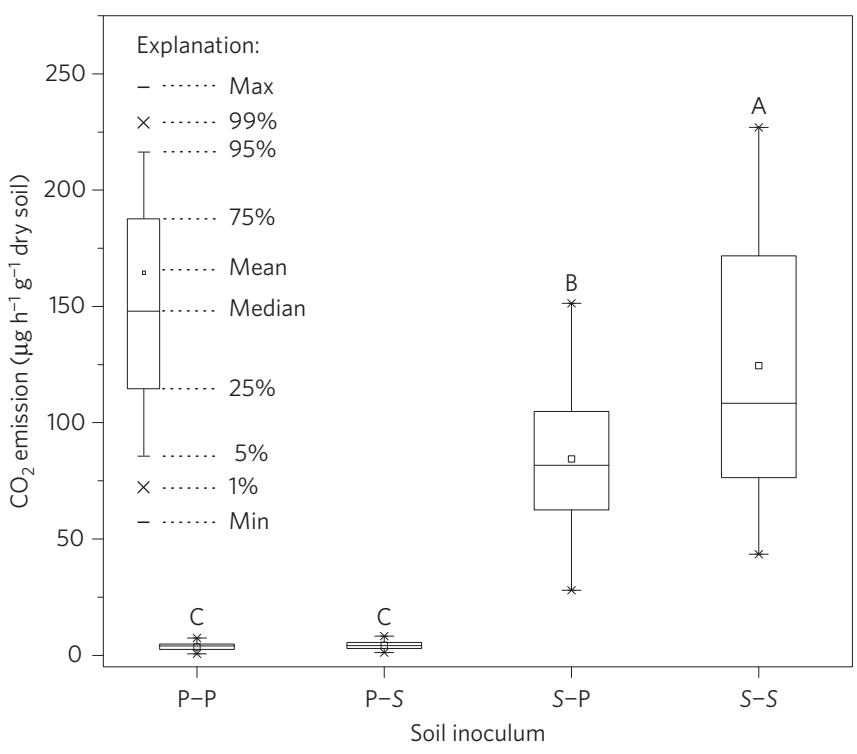

Figure $4 \mid \mathrm{CO}_{2}$ emissions from pocosin and boreal Sphagnum peat treated with pocosin peat or Sphagnum peat inocula during the drought phase.

$\mathrm{P}$-pocosin, S-Sphagnum. Different letters indicate significant differences among treatments.

We further tested whether shrub expansion in Sphagnum peatlands can preserve carbon stores by a drought-rewetting experiment. Sphagnum and pocosin inocula were used for reciprocal amendments in Sphagnum and pocosin soils. Pocosin inoculum significantly reduced Sphagnum peat decomposition during drought (Fig. 4). Consistent with other studies ${ }^{2,3,14,15}$, drought raised SR in Sphagnum peat, but not in pocosin peat before the low soil moisture limited microbial activity (Supplementary Fig. 7). Although Sphagnum peat had higher soil moisture in this experiment, it decomposed 20-150 times faster than shrub peat at the same temperature (Fig. 4 and Supplementary Fig. 7), which supports our phenolics findings (Figs 2 and 3 ) and indicates that decomposition of Sphagnum peat is more sensitive to drought and warming. These data suggest that an adaptive shift from Sphagnum to shrubs would probably offset some effects of drought and warming ${ }^{27}$. Huge pulse emissions of $\mathrm{CO}_{2}$ also occurred after rewetting, as in other studies ${ }^{3}$, but quickly dropped to the initial level (Supplementary Fig. 7), which further indicates that peatlands are complex adaptive system with built-in high resilience ${ }^{6}$.

Other than phenol oxidase activity and the composition of plant communities, drought also increases the availability of nitrogen that may negatively impact phenolics ${ }^{28}$. We added nitrogen to pocosin soil in the laboratory. A 73\% reduction of phenolics was found after 7 days (Supplementary Fig. 8). Therefore, nitrogen increases HR not only by boosting microbial activity directly but also by reducing phenolics indirectly ${ }^{29}$. In the drained sites, lower soil phenolics were thus probably caused by both low-phenolic ferns and droughtinduced higher nitrogen (Supplementary Table 3). Although trees in the natural site had high phenolics, the higher reactive nitrogen feasibly reduced phenolics there as well (Supplementary Fig. 4b,f). Compared with drained and natural sites, soil in the restored sites contained the lowest reactive nitrogen (Supplementary Fig. 4f), which was conducive to sustaining high phenolics in soil.

Taken together, our studies show dual controls on carbon loss by phenolics build-up during both short- and long-term drought. We demonstrate that shrub expansion as an adaptive succession in the face of climate change not only increases carbon sequestration by producing high-phenolic peat with low nitrogen but can also protect buried historic Sphagnum or fern/sedge (low phenolics) peat. We therefore postulate that moderate drought might have only minor short-term impacts on decomposition in phenolic-laden peat and that the projected catastrophic 'positive feedback loop' between carbon emission and drought ${ }^{2,3,14,15}$ might not occur in the long term. Our studies show how phenolics are formed and affected by external forces, which is a key aspect of peatland carbon storage. However, it is still unclear what specific components or groups of phenolics are vital because plants produce and contain thousands of compounds that function differently. We anticipate our study to be a starting point for detailed carbon chemistry and comprehensive long-term studies to further explore these processes. These studies would have important potential applications for better coping with and mitigating upcoming climate changes in wetlands and other ecosystems $s^{30}$.

\section{Methods}

Methods and any associated references are available in the online version of the paper.

Received 4 December 2014; accepted 26 March 2015; published online 11 May 2015

\section{References}

1. Joosten, $\mathrm{H}$. The Global Peatland $\mathrm{CO}_{2}$ Picture. Peatland Status and Drainage Related Emissions in All Countries of The World (Ede, 2010).

2. Bragazza, L., Parisod, J., Buttler, A. \& Bardgett, R. D. Biogeochemical plant-soil microbe feedback in response to climate warming in peatlands. Nature Clim. Change 3, 273-277 (2012).

3. Fenner, N. \& Freeman, C. Drought-induced carbon loss in peatlands. Nature Geosci. 4, 895-900 (2011).

4. Dorrepaal, E. et al. Carbon respiration from subsurface peat accelerated by climate warming in the subarctic. Nature 460, 616-619 (2009).

5. Belyea, L. R. \& Baird, A. J. Beyond "the limits to peat bog growth": Cross-scale feedback in peatland development. Ecol. Monogr. 76, 299-322 (2006).

6. Dise, N. Environmental science. Peatland response to global change. Science 326, 810-811 (2009).

7. Carter, M. S. et al. Synthesizing greenhouse gas fluxes across nine European peatlands and shrublands-responses to climatic and environmental changes. Biogeosciences 9, 3739-3755 (2012)

8. Muhr, J., Hoehle, J., Otieno, D. O. \& Borken, W. Manipulative lowering of the water table during summer does not affect $\mathrm{CO}_{2}$ emissions and uptake in a fen in Germany. Ecol. Appl. 21, 391-401 (2011).

9. Turetsky, M. R., Donahue, W. F. \& Benscoter, B. W. Experimental drying intensifies burning and carbon losses in a northern peatland. Nature Commun. 2, 514 (2011).

10. Laiho, R. Decomposition in peatlands: Reconciling seemingly contrasting results on the impacts of lowered water levels. Soil Biol. Biochem. 38, 2011-2024 (2006).

11. Noormets, A. et al. Response of carbon fluxes to drought in a coastal plain loblolly pine forest. Glob. Change Biol. 16, 272-287 (2010).

12. Laiho, R., Vasander, H., Penttilä, T. \& Laine, J. Dynamics of plant-mediated organic matter and nutrient cycling following water-level drawdown in boreal peatlands. Glob. Biogeochem. Cycles 17, 1053 (2003).

13. Elmendorf, S. C. et al. Plot-scale evidence of tundra vegetation change and links to recent summer warming. Nature Clim. Change 2, 453-457 (2012).

14. Ise, T., Dunn, A. L., Wofsy, S. C. \& Moorcroft, P. R. High sensitivity of peat decomposition to climate change through water-table feedback. Nature Geosci. 1, 763-766 (2008)

15. Freeman, C., Ostle, N. \& Kang, H. An enzymic 'latch' on a global carbon store-A shortage of oxygen locks up carbon in peatlands by restraining a single enzyme. Nature 409, 149 (2001).

16. Moore, S. et al. Deep instability of deforested tropical peatlands revealed by fluvial organic carbon fluxes. Nature 493, 660-663 (2013).

17. Makiranta, P. et al. Indirect regulation of heterotrophic peat soil respiration by water level via microbial community structure and temperature sensitivity. Soil Biol. Biochem. 41, 695-703 (2009).

18. Rousk, J., Smith, A. \& Jones, D. Investigating the long-term legacy of drought and warming on the soil microbial community across five European shrubland ecosystems. Glob. Change Biol. 19, 3872-3884 (2013).

19. Oechel, W. C. et al. Acclimation of ecosystem $\mathrm{CO}_{2}$ exchange in the Alaskan Arctic in response to decadal climate warming. Nature 406, 978-981 (2000).

20. Richardson, C. J. in Wetland Habitats of North America (eds Baldwin, D. P. \& Batzer, A. H.) 189-202 (Univ. California Press, 2012). 
21. Bakker, S. A., Jasperse, C. \& Verhoeven, J. T. A. Accumulation rates of organic matter associated with different successional stages from open water to carr forest in former turbaries. Plant Ecol. 129, 113-120 (1997).

22. Toberman, H. et al. Long-term drainage for forestry inhibits extracellular phenol oxidase activity in Finnish boreal mire peat. Eur. J. Soil Sci. 61, 950-957 (2010)

23. Toberman, H. et al. Summer drought effects upon soil and litter extracellular phenol oxidase activity and soluble carbon release in an upland Calluna heathland. Soil Biol. Biochem. 40, 1519-1932 (2008).

24. Turetsky, M. R., Crow, S. E., Evans, R. J., Vitt, D. H. \& Wieder, R. K. Trade-offs in resource allocation among moss species control decomposition in boreal peatlands. J. Ecol. 96, 1297-1305 (2008).

25. Reiche, M., Hadrich, A., Lischeid, G. \& Kusel, K. Impact of manipulated drought and heavy rainfall events on peat mineralization processes and source-sink functions of an acidic fen. J. Geophys. Res. 114, G02021 (2009).

26. McClymont, E. L. et al. Pyrolysis GC-MS as a rapid screening tool for determination of peat-forming plant composition in cores from ombrotrophic peat. Org. Geochem. 42, 1420-1435 (2011)

27. Ward, S. et al. Warming effects on greenhouse gas fluxes in peatlands are modulated by vegetation composition. Ecol. Lett. 20, 1285-1293 (2013).

28. Bragazza, L. et al. Atmospheric nitrogen deposition promotes carbon loss from peat bogs. Proc. Natl Acad. Sci. USA 103, 19386-19389 (2006).

29. Bragazza, L. \& Freeman, C. High nitrogen availability reduces polyphenol content in Sphagnum peat. Sci. Total Environ. 377, 439-443 (2007).
30. Freeman, C., Fenner, N. \& Shirsat, A. H. Peatland geoengineering: An alternative approach to terrestrial carbon sequestration. Phil. Trans. $R$ Soc. A 370, 4404-4421 (2012).

\section{Acknowledgements}

We would like to thank W. Willis and J. Bills for the field and laboratory measurement, R. Neighbarger for technical editing, N. Flanagan for providing water level data and T. Moore at McGill University for collection of Mer Bleue Sphagnum peat. Thanks also go to S. Ward and D. Kitts, USFWS, for helping with site selections and field assistance. Coastal Carolina/Southeastern Virginia Strategic Habitat Conservation Team, US Fish and Wildlife Service-Region 4, The Nature Conservancy of North Carolina, US DOE Office of Science, Terrestrial Ecosystem Sciences, under grant award DE-SC0012272 and the Duke University Wetland Center Endowment provided financial support.

\section{Author contributions}

H.W. and C.J.R. designed the study, H.W. and M.H. conducted the research, H.W. analysed the data and wrote the manuscript with C.J.R., and all authors discussed results and commented on the manuscript.

\section{Additional information}

Supplementary information is available in the online version of the paper. Reprints and permissions information is available online at www.nature.com/reprints. Correspondence and requests for materials should be addressed to H.W. or C.J.R.

\section{Competing financial interests}

The authors declare no competing financial interests. 


\section{Methods}

Field experiments. Static chambers were used to measure soil respiration (August 2011-January 2013) in pocosins. Surface soil was sampled for chemical analysis, and related environmental variables were monitored simultaneously. $\mathrm{CO}_{2}$ concentration was determined by a gas chromatograph. Soil respiration was calculated from the linear increase of $\mathrm{CO}_{2}$ concentrations with time. Deionized water and $70 \%$ acetone were used to extract the water-soluble and total phenolics from milled senescent leaves. Above-ground biomass was estimated on the basis of allometric equations for each species and field plot measurements of tree and shrub diameters as well as satellite photos for spatial analysis of canopy coverage.

Drought experiment. Triplicate peat monoliths were collected from natural, drained and restored pocosins and incubated in microcosms $(30-\mathrm{cm}$ diameter, $37.5-\mathrm{cm}$ depth) simulating natural drought by evaporation for 5 months. Roots were removed from these microcosms, so only heterotrophic respiration was measured by a portable LiCor-6400-XT infrared gas analyser. Related chemical parameters of soil were measured 4 times during the incubation.

Drought-rewetting experiment. Wooded and Sphagnum peat samples (depths of $10-20 \mathrm{~cm}$ ) were collected from pocosins in the US and Mer Bleue peatlands in Canada. Inoculum was prepared by mixing each type of peat with deionized water and a reciprocal-inoculation experiment was performed in triplicate jars in the laboratory. Natural drought and a heavy storm were simulated by evaporation and rewetting. We collected gas samples from the jar headspace at the beginning and end of 1-h incubation and used a Varian-450 gas chromatograph to analyse $\mathrm{CO}_{2}$ concentration, and then converted the $\mathrm{CO}_{2}$ concentrations to emission rates.

Nitrogen-enriched experiment. We compared the concentration of phenolics in nitrogen-enriched and controlled (nitrogen unenriched) pocosin soil after a 7-d incubation in the laboratory. 